acids dissolved. Ammoniacal cobalt nitrate behaved in the same way. The barium salt, emerald-green in color and insoluble in water, dissolved on the addition of a few drops of acid.

Analysis :

\begin{tabular}{|c|c|c|c|c|}
\hline & \multicolumn{3}{|c|}{ Found. } \\
\hline & & $\begin{array}{c}\text { I. } \\
\text { Per cent. } \\
6.47\end{array}$ & $\begin{array}{c}\text { II. } \\
\text { Per cent. } \\
6.29\end{array}$ & $\begin{array}{c}\text { III. } \\
\text { Per cent. } \\
6.33\end{array}$ \\
\hline $\mathrm{V}_{2} \mathrm{O}, \ldots \ldots \ldots \ldots$ & 8.15 & 8.30 & 8.28 & $\cdots$ \\
\hline $\mathrm{WO}_{3} \ldots \ldots \ldots \ldots$ & 79.72 & 79.27 & 79.56 & 80.43 \\
\hline $\mathrm{H}_{2} \mathrm{O} \ldots \ldots \ldots \ldots$ & $5 \cdot 75$ & 5.96 & 5.87 & $\cdots$ \\
\hline
\end{tabular}

[CONTRIBUTION FROM THE JOHN HARRISON LABORATORY OF CHEMISTRY, No. 79.]

\title{
DERIVATIVES OF COMPLEX INORGANIC ACIDS.
}

[FIFTH PAPER.]

By Clarence W. Balke aND EDGaR F. SMith.

Recelved September 25, 1903 .

FIFTY years ago Struve made double molybdates, which he believed were analogous to the alums. Wolcott Gibbs showed that the products of Struve's efforts were salts of "complex inorganic acids," in which the various sesquioxides, together with molybdenum trioxide, constituted the several anions in union with protoxides-cathions. It was Struve's intention to prepare analogous tungstates. He never described any of these and, in order to complete certain gaps in a line of inquiry, upon which we have been engaged, we undertook the preparation of compounds following the general types

$$
\begin{aligned}
& \mathrm{R}_{2} \mathrm{O} . x \quad \mathrm{Al}_{2} \mathrm{O}_{3} \quad y \quad \mathrm{WO}_{3} \text {. } \\
& \mathrm{R}_{2} \mathrm{O} \text {. } x \boldsymbol{F e}_{2} \mathrm{O}_{3} y \mathrm{WO}_{3} \text {. } \\
& \mathrm{R}_{2} \mathrm{O} . x \mathrm{Cr}_{2} \mathrm{O}_{3} \text { y } \mathrm{WO}_{3} \text {. } \\
& \text { R. O. } x \mathrm{Ni}_{2} \mathrm{O}_{3} \text {. y } \mathrm{WO}_{3} \text {. } \\
& \mathrm{R}_{2} \mathrm{O}, x \mathrm{Mn}_{2} \mathrm{O}_{3}, y \mathrm{WO}_{3} \text {. } \\
& \mathrm{R}_{2} \mathrm{O} . x \mathrm{Bi}_{2} \mathrm{O}_{3} \text { y } \mathrm{WO}_{3} \text {, etc. }
\end{aligned}
$$

All of these have been made. In this communication, however, we shall only describe those derivatives in which aluminum and bismuth oxide are present. The remaining bodies will be 
further studied and efforts will be made to introduce certain other sesquioxides. We have also made a number of bodies of these types:

$$
\begin{aligned}
& \mathrm{R}_{2} \mathrm{O} . x \mathrm{Fe}_{2} \mathrm{O}_{3} \cdot y \mathrm{P}_{2} \mathrm{O}_{5} . \approx \mathrm{WO}_{3} . \\
& \mathrm{R}_{2} \mathrm{O} . x \mathrm{Ni}_{2} \mathrm{O}_{3} \cdot y \mathrm{P}_{2} \mathrm{O}_{5} . \approx \mathrm{WO}_{3}, \text { etc., etc. }
\end{aligned}
$$

It may be mentioned that the introduction of the pentoxide apparently increased the stability of the resulting body and caused it to crystallize in a more definite and pronounced form.

$$
\begin{gathered}
\text { AMMONIUM ALUMINICO-TUNGSTATE, } \\
3\left(\mathrm{NH}_{4}\right)_{2} \mathrm{O} \cdot \mathrm{Al}_{2} \mathrm{O}_{3} \cdot 9 \mathrm{WO}_{3} \cdot 4 \mathrm{H}_{2} \mathrm{O} .
\end{gathered}
$$

This salt was made by boiling freshly precipitated and thoroughly washed aluminum hydroxide, in excess, with ammonium paratungstate for from fifteen to twenty hours, when the solution was allowed to drain through a folded filter. On evaporating the clear liquid upor: a water-bath, a dense, highly refracting sirup appeared. Glass floated on it. On exposure to the air, it dried to a semitransparent mass. It seemed to be a very stable body. Ammonium hydroxide added to its solution did not produce a precipitate. Its dilute solutions were not affected in the hot or cold by dilute hydrochloric or nitric acids.

The dry, powdered salt dissolved in concentrated nitric acid; precipitation did not occur, even upon boiling. The salt was solubie also in concentrated hydrochloric acid without the production, in the cold, of a precipitate, but when the solution was vigorously boiled a yellow-colored precipitate separated. Mercurous nitrate produced, in its aqueous solution, a yellowish whitecolored precipitate. The precipitate caused by barium chloride was almost insoluble in hot water. After drying, acids failed to dissolve it. In a slightly ammoniacal solution of the salt, silver nitrate produced a yeilowish white precipitate, which proved to be soluble in a large volume of hot water.

\section{ANALYSIS.}

The powdered, air-dried salt was further dried by exposure, for several hours, to the temperature of a water-bath. A weighed portion was then ignited at a low red heat in a tared porcelain crucible. The loss it sustained represented water and ammonium oxide. The ignited material was next fused with potassium bisulphate. The fused mass was digested with $125 \mathrm{cc}$. of water, 
I5 cc. of nitric acid, and several drops of hydrochloric acid. When the decomposition was complete, the solution was filtered and the aluminum precipitated, with ammonium hydroxide, from the clear liquid. Whenever the resulting aluminum oxide was contaminated with tungstic oxide the fusion was repeated. The amnonium oxide was determined in the usual manner.

Results :

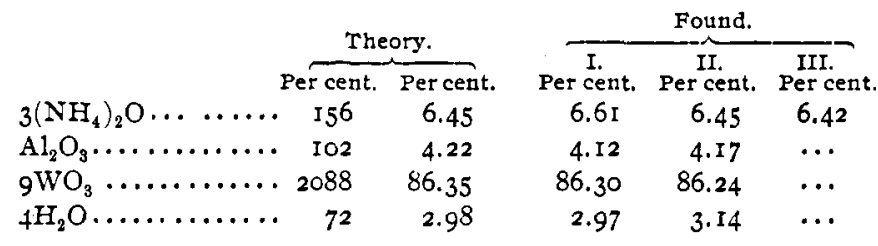

SILVER AMMONIUM ALUMINICO-TUNGSTATE,$$
\text { I I } \mathrm{Ag}_{2} \mathrm{O} .2 \mathrm{I}\left(\mathrm{NH}_{4}\right)_{2} \mathrm{O} .4 \mathrm{Al}_{2} \mathrm{O}_{3} .36 \mathrm{WO}_{3} \text {. }
$$

A yellowish white precipitate was produced when silver nitrate was added to a distinctly ammoniacal solution of the preceding salt. This precipitate was washed with cold water, in which it proved to be but sparingly soluble. Or, it was dissolved in a large volume of hot water, made ammoniacal. The filtrate was allowed to stand, when a crystalline mass separated from it on cooling. Analyses of the precipitated salt and the crystalline body showed them to be identical in composition. Air-dried samples were used for the analysis. The perfectly dry salt was quite insoluble in pure water, but readily soluble in water containing ammonia or nitric acid. Mercurous nitrate, introduced into the nitric acid solution, produced a yellowish white precipitate, readily soluble in hot water.

Analysis.-The silver was determined as chloride in the nitric acid solution of the salt, while the other constituents were estimated as described under the ammonium salt. The loss upon ignition was found to equal the ammonium oxide determined directly.

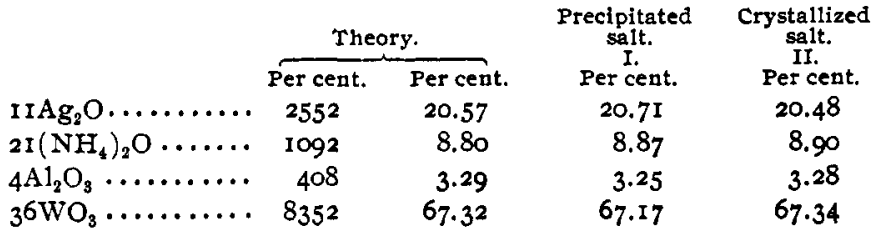


If the sum of the protoxides be taken, the formula would read

$$
32 \mathrm{R}_{2} \mathrm{O} .4 \mathrm{Al}_{2} \mathrm{O}_{3} \cdot 36 \mathrm{WO}_{3} \text {, }
$$

which would furnish the simple formula

when divided by four.

$$
8 \mathrm{R}_{2} \mathrm{O} . \mathrm{Al}_{2} \mathrm{O}_{3} \cdot 9 \mathrm{WO}_{3}
$$

It may be observed here that Klein ${ }^{1}$ has represented the most stable series of borico-tungstates by the general formula

$$
2 \mathrm{R}_{2} \mathrm{O} \cdot \mathrm{B}_{2} \mathrm{O}_{3} \cdot 9 \mathrm{WO}_{3} \cdot \mathrm{xH}_{2} \mathrm{O} \text {. }
$$

AMMONIUM BISMUTHICO-TUNGSTATE,

$$
3\left(\mathrm{NH}_{4}\right)_{2} \mathrm{O} .2 \mathrm{Bi}_{2} \mathrm{O}_{3} \text {. II } \mathrm{WO}_{3} \cdot \operatorname{IOH}_{2} \mathrm{O} \text {. }
$$

On boiling well-washed bismuth metahydroxide with ammonium paratungstate for two days, it dissolved in large amount, so that it was necessary to make additions of it from time to time. The solution, filtered from the excess, had a yellow color. It was evaporated to complete dryness and the residue then exhausted with a small quantity of hot water, the solution filtered and allowed to cool, when ammonium bismuthico-tungstate separated as an oil, having a specific gravity slightly above 3.6. This oil, after being washed carefully several times with cold water, dried to a transparent, yellow-colored glass. No precipitate was produced on strongly diluting the solution of this salt with water. Amnonium hyclroxicle caused no change in its cold dilute solutions, but when the latter were boiled in the presence of ammonia, a copious white precipitate separated. Nitric acid caused no change in the boiling dilute solutions of the salt, but in concentrated solutions precipitation occurred on the addition of concentrated nitric acid. The addition of a large volume of hot water again effected solution. Hydrochloric acid occasioned no change in cold or hot dilute solutions, while tungstic acid

\begin{tabular}{|c|c|c|}
\hline & \multicolumn{2}{|c|}{ Theory. } \\
\hline & $\begin{array}{c}\text { Per } \\
\text { cent. }\end{array}$ & $\begin{array}{l}\text { Per } \\
\text { cent. }\end{array}$ \\
\hline $3\left(\mathrm{NH}_{4}\right)_{2} \mathrm{O} \ldots$ & 156 & 4.09 \\
\hline $2 \mathrm{Bi}_{2} \mathrm{O}_{3} \ldots \ldots$ & $93^{\circ}$ & $24 \cdot 36$ \\
\hline $\mathrm{IIWO}_{3} \ldots$ & 2552 & $66.8_{3}$ \\
\hline $\mathrm{IOH}_{2} \mathrm{O} \ldots \ldots$ & I 80 & 4.72 \\
\hline
\end{tabular}
separated on boiling with concentrated hydrochloric acid. Mercurous nitrate precipitated yellowish white mercurous bismuthicotungstate. The results of the analysis were:

Found.

$\begin{array}{ccc}\overbrace{\text { I. }} & \text { II. } & \text { III. } \\ \text { Per cent. } & \text { I'er cent. } & \text { Per cent. } \\ 4.34 & 4.28 & 4.14 \\ 24.3 \mathrm{I} & 24.22 & 25.00 \\ 66.59 & 67.07 & 66.3 I \\ 4.76 & 4.43 & 4.50\end{array}$


POTASSIUM BISMUTHICO-TUNGSTATE,

$$
3 \mathrm{~K}_{2} \mathrm{O} .2 \mathrm{Bi}_{2} \mathrm{O}_{3} \text {. I I } \mathrm{WO}_{3} \text {. I } 5 \mathrm{H}_{2} \mathrm{O} \text {. }
$$

This salt separated in the form of a yellow-colored oil, upon adding a hot saturated solution of potassium bromide to a concentrated solution of ammonium bismuthico-tungstate. On conling, the oil sometimes showed crystals which were very soft and gummy in appearance. It was discovered to be best, when the oil had become viscous and gum-like, to warm it again with a saturated solution of potassium bromide, after which it was repeatedly washed with small volumes of warm water. It was then dried on the water-bath to a transparent, pale lemon-yellow colored glass.

Analysis.-Except for the determination of the potassium the method pursued in the preceding analyses was adopted. In estimating the potassium, a weighed amount of the "glass" was covered with water and mercurous nitrate added in slight excess. Ammonium hydroxide was added to alkaline reaction, the excess of it being expelled by boiling. A few drops more of mercurous nitrate were introduced and, after standing half an hour, the precipitate was filtered off and thoroughly washed with warm water. The filtrate, after acidulation with dilute sulphuric acid, was charged with hydrogen sulphide. The filtrate from the mercury sulphide was evaporated and the potassium obtained as sulphate.

Results :

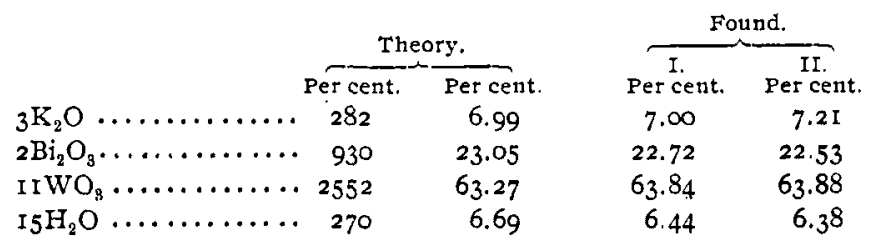

STRONTIUM BISMUTHICO-TUNGSTATE,

$$
3 \mathrm{SrO}_{2} \mathrm{Bi}_{2} \mathrm{O}_{3} \text {. II } \mathrm{IOO}_{3} \text {. I I } \mathrm{IH}_{2} \mathrm{O} \text {. }
$$

This salt was made by transposing the potassium salt with a saturated solution of strontium chloride. The product was an insoluble yellow-colored oil, which was washed with hot water to remove all soluble impurities. When cooled, the oil changed to a yellow wax. It was insoluble in pure water, but dissolved readily upon the addition of a few drops of nitric acid. Dried 
upon a water-bath, it changed to a hard, vitreous mass. The determination of the strontium was made as described under the potassium salt.

Results :

\begin{tabular}{|c|c|c|c|c|}
\hline & \multirow{2}{*}{\multicolumn{2}{|c|}{ Theory. }} & \multicolumn{2}{|c|}{ Found. } \\
\hline & & & & \\
\hline & $\begin{array}{c}\text { Per cent. } \\
3 \text { II }\end{array}$ & $\begin{array}{c}\text { Per cent. } \\
7.79\end{array}$ & $\begin{array}{c}\text { Per cent. } \\
6.80\end{array}$ & $\begin{array}{c}\text { Per cent. } \\
\ldots .\end{array}$ \\
\hline $2 \mathrm{Bi}_{2} \mathrm{O}_{3} \ldots \ldots \ldots \ldots$ & 930 & 23.30 & 23.07 & 23.42 \\
\hline $\mathrm{II} \mathrm{WO}_{3} \ldots \ldots \ldots \ldots$ & 2552 & 63.95 & $\ldots$ & $\ldots$ \\
\hline $\mathrm{I}_{\mathrm{I}} \mathrm{H}_{2} \mathrm{O} \ldots \ldots \ldots \ldots$ & 198 & 4.96 & 4.96 & 4.95 \\
\hline
\end{tabular}

The purpose of this study will be to ascertain to what extent the more metallic sesquioxides can be introduced into such complexes as have been indicated in the preceding paragraphs, and to exhaustively investigate their derivatives before advancing to those compounds in which there will appear the additional pentoxide.

Columbo- and tantalo-tungstates of sodium and ammonium have been made and analyzed, but a description of them will be reserved for a later communication.

UNiversity of Pexnsyluamia.

\section{THE INFLUENCE OF SOIL MOISTURE UPON THE CHEMICAL COMPOSITION OF CERTAIN PLANT PARTS.}

BY JOHN A, WIDTSOE.

Received Octobez 7, 1903.

THE great variation in the chemical composition of plants grown under the same climatic conditions and upon similar soils, has always been a somewhat mystifying phenomenon to students of plant chemistry. That plant composition is influenced by soil composition is beyond question; and it is quite generally believed that sunshine, temperature and soil moisture are factors in controlling the chemical composition of plants. However, the relative and absolute values of these soil, climatic and water factors have not been determined, even approximately; and the observed variation in plant composition has usually been beyond satisfactory explanation. In view of this lack of knowledge, it was 